\title{
Corrupción y formas de gobierno
}

\section{Antonio Fiménez-Blanco Carrillo de Albornoz}

RESUMEN: Entre las causas de la corrupción las hay o puede haber culturales, estructurales e institucionales. Cabe preguntarse si, dentro de estas últimas, se encuentra la que distingue, dentro de los Estados democráticos, entre formas de gobierno presidencialistas y parlamentarias. En el bien entendido de que la comparación, aplicada a un determinado país, no puede hacerse sobre magnitudes homogéneas, porque estamos comparando una realidad y una mera conjetura.

El autor parte de la base de España (un régimen parlamentario según la Constitución de 1978) y en la que todos los indicadores, sea cual fuere su grado de fiabilidad, arrojan unos elevados índices de corrupción, sobre todo en el período de expansión económica 1996-2008.

El trabajo, que por supuesto comienza poniendo de relieve la dificultad de ofrecer un concepto preciso y universal de corrupción, así como la convergencia entre ambas formas de gobierno, concluye que entre las causas institucionales de la corrupción no tiene por qué encontrarse la forma de gobierno. Y en particular sostiene la idea de que el parlamentarismo no significa necesariamente una mejora con respecto al presidencialismo.

PALABRAS CLAVE: Corrupción - Formas de Gobierno - Gobierno Parlamentario - Gobierno Presidencialista

\section{PLANTEAMIENTO ${ }^{1}$}

1. La pregunta -dando por supuesto que la corrupción (la pública) es siempre una patología: la teoría de la corrupción como aceite beneficioso no resulta aceptable para el autor- es si, entre los factores de los que depende el grado de corrupción de un país (democrático, porque las autocracias son otra cosa, entendiendo por democrá-

$1 \quad$ El presente trabajo se inscribe en los estudios realizados en el marco del Proyecto I+D DER201679920-R "La lucha por la ética y contra la corrupción: empleo y contratación del sector público, urbanismo y actividad de fomento de los poderes locales" financiado por el Gobierno de España y la Unión Europea y fue objeto de presentación en el panel "La integridad pública: puntos de reflexión y análisis para mejorar el desempeño institucional” en el marco del XXIV Congreso Internacional del CLAD, que se realizó en Buenos Aires, Argentina, del 12 al 15 de noviembre de 2019.

Recibido: 09/09/2019

Aceptado: 20/09/2019 
tico, como mínimo, que cuenta con un Parlamento elegido por sufragio universal y libre), se encuentra su marco institucional y en concreto su forma de gobierno, presidencialista o parlamentaria, según que la división de poderes sea estricta y el Jefe de Estado (o, en su caso, de Gobierno: el primer ejecutivo, para entendernos) venga con legitimación popular propia o, por el contrario, proceda de dicho Parlamento. En principio, pudiera pensarse intuitivamente que lo primero, por su acentuado componente personalista, la ayudaría y lo segundo la mitigaría, pero es sólo una primera aproximación y se trata de ver si acaso se puede confirmar científicamente. Lo que, habida cuenta que desde Galileo el lenguaje de la ciencia está representado por las matemáticas, significa cuantificación. O, si se prefiere, parametrización.

La corrupción es algo por esencia oculto, pero eso no significa que no se hayan desarrollado instrumentos de medida más o menos perfectos. A saber:

- Los datos judiciales (sobre todo, de la justicia criminal) sobre delitos de corrupción, lo que tiene el inconveniente, de entrada, de identificar corrupción con ilegalidad y más aún con ilegalidad penal. A lo que hay que añadir el hecho obvio de que ese método deja al margen los supuestos de impunidad, hasta el punto de poderse decir que lo que verdaderamente se está midiendo es la calidad del sistema institucional y no la corrupción en sí. De acuerdo con ese criterio, en la desdichada Haití, por ejemplo, donde no se persigue a nadie por robar, no habría corrupción.

- Las encuestas de percepción, que, con una opinión pública tan desinformada sobre la realidad del momento, tampoco constituyen dogmas de fe. El caso de España resulta paradigmático. Hoy sabemos que cuando la corrupción se multiplicó e institucionalizó fue en el período de bonanza económica de 1996-2008, siendo así que en esa época la preocupación por el asunto se encontraba ausente en la ciudadanía. Por el contrario, la crisis económica, que además coincidió con la explosión de medios de información no convencionales, provocó (con rezago) la sensación de que estábamos ante una atmósfera asfixiante, muy en particular cuando la tal crisis llevó a la necesidad de recortes en el gasto público que sufrieron de manera más aguda los sectores sociales desfavorecidos. 
Pero eso no significa que las encuestas no valgan, sobre todo si se agregan para generar índices compuestos, como el "Índice de Percepción de la Corrupción de 2017” de Transparencia Internacional (2018), y que, en lo que hace a nuestra familia, los iberoamericanos, arroja el siguiente cuadro:

\begin{tabular}{|c|l|c|c|c|}
\hline $\begin{array}{c}\text { Ranking de } \\
\text { países 2016 } \\
\text { (sobre 176 países) }\end{array}$ & $\begin{array}{c}\text { Países } \\
\text { iberoamericanos }\end{array}$ & 2016 Puntos & 2014 Puntos & 2012 Puntos \\
\hline 21 & Uruguay & 71 & 73 & 72 \\
\hline 24 & Chile & 66 & 73 & 72 \\
\hline 29 & Portugal & 62 & 63 & 63 \\
\hline 41 & España & 58 & 60 & 65 \\
\hline 41 & Costa Rica & 58 & 54 & 54 \\
\hline 60 & Cuba & 47 & 46 & 48 \\
\hline 79 & Brasil & 40 & 43 & 43 \\
\hline 87 & Panamá & 38 & 37 & 38 \\
\hline 90 & Colombia & 37 & 37 & 36 \\
\hline 95 & Argentina & 36 & 34 & 35 \\
\hline 95 & El Salvador & 36 & 39 & 38 \\
\hline 101 & Perú & 35 & 38 & 38 \\
\hline 113 & Bolivia & 33 & 35 & 34 \\
\hline 120 & Re. Dominicana & 31 & 32 & 32 \\
\hline 120 & Ecuador & 31 & 33 & 32 \\
\hline 123 & Honduras & 30 & 29 & 28 \\
\hline 123 & México & 30 & 35 & 34 \\
\hline 123 & Paraguay & 30 & 24 & 25 \\
\hline 136 & Guatemala & 28 & 32 & 33 \\
\hline 145 & Nicaragua & 26 & 28 & 29 \\
\hline 166 & Venezuela & 17 & 19 & 19 \\
\hline-15 & & & & \\
\hline
\end{tabular}

- Un tercer método consiste en las llamadas "encuentros de victimización”, que presentan el inconveniente de tener por objeto sólo los sobornos (¿ile han pedido a Vd. dinero por algo?) y en las que, curiosamente, en España, sobre todo en lo que tiene que ver con la sanidad pública, los índices son inmaculados.

- En cuarto y último lugar, no hará falta decir que al arsenal de instrumentos de medición de la corrupción también ha terminado llegando el big data. El FMI ha creado el News Flow Index of Corruption, que tiene en cuenta las noticias de co- 
rrupción (NIG) y de anticorrupción (anti-NIG) como ha señalado Villoria Mendieta (2019: 33 a 66).

Para la exposición detallada de cada uno de esos métodos y de sus fortalezas y debilidades haría falta todo un Tratado. Lo cierto es que, bien o mal, parámetros existen e instrumentos de medida igualmente.

Y eso sin contar con lo que son cálculos en cifras absolutas. El Grupo de los Verdes/Alianza Libre Europa publicó en diciembre de 2018 el estudio "The cost of corruption across EU", que la estimaban en 904.000 millones de Euros anuales. De ellos, 90.000 millones en España, lo que significa aproximadamente el 8 por ciento del PIB. Sobre su fiabilidad no puedo pronunciarme, por haber aparecido sólo en la prensa, en concreto en el periódico ABC el 8 de diciembre de 2018.

\section{PUNTUALIZACIONES ADICIONALES}

Todo eso sin contar con el hecho de que el propio concepto de corrupción (pública) se muestra difuso y de difícil precisión. En la España de los últimos años la bibliografía resulta inabarcable y de la mejor y más moderna doctrina -y por supuesto teniendo en cuenta la Convención de Naciones Unidas contra la Corrupción, que en junio de 2018 ya contaba con 186 firmantes y ratificantes- podemos resaltar los siguientes seis rasgos:

- Se trata de "una relación bilateral entre un agente público (altos cargos y empleados públicos) y otro privado, que negocian o convienen en relación con cierto objeto que es el poder, en concreto, cierto acto, que el agente público puede producir o dejar de producir en ejercicio del cargo que ostenta. A cambio de tal activo, bien o mercancía, el privado está dispuesto a abonar o entregar al primero, al público, una ventaja que puede revestir distintas formas".

- Que la relación la haya desencadenado el uno o el otro puede tener transcendencia a efectos del castigo o consecuencia jurídica, pero nada más.

- La tal relación presenta naturaleza esencialmente comercial o económica y tiene carácter intencional o, dicho en términos penales, dolosa.

- La "mercancía" objeto de la transacción -un hacer o un no hacer- debe formar parte del ámbito de las funciones propias del cargo. Por eso, al menos desde la perspectiva de la competencia para adoptar la decisión, ofrece una imagen inicial de legalidad.

- “(...) el agente privado abona al agente público una contrapartida en forma de ventaja que, como se ha indicado, puede ser de distintos tipos o, incluso, diferentes 
destinatarios. Puede consistir desde el abono de una cantidad (en metálico) hasta el reconocimiento de un beneficio a un tercero vinculado con el agente público de tal modo que éste se pueda sentir obligado a corresponder".

- “(...) la relación bilateral corrupta es una relación que se desarrolla al margen del Derecho y en contra del Derecho", Betancor (2017).

En afirmaciones tan genéricas y angelicales podemos coincidir todos, pero la cosa se complica si, para explicarlo con las conocidas palabras de Lope de Vega, pasamos de las musas al teatro. Es notorio que en cualquier país del mundo se produce lo que se conoce como "captura del Estado" (o "del regulador"), en el sentido de que su ámbito real de decisión, en teoría amplísimo, se encuentra condicionado por las circunstancias ambientales, por así decir. En el caso típico y más grosero, los pagos privados ilícitos y no transparentes a los partidos o a las personas (por ejemplo, para contribuir a su campaña electoral), pero hay veces en que el mismo efecto se produce de manera menos ofensiva, mediante sutilezas como la promesa de un buen trato por los medios de comunicación. ¿Dónde está la raya que en esos casos delimita la frontera de lo corrupto y de lo que no lo es?

Por no hablar del clientelismo, cuyas manifestaciones no sólo son legales (en España, mediante la designación de personas para los llamados "puestos de confianza" o la selección entre los afines de beneficiarios del gasto público) sino que la sociedad las contempla como la manera normal de gobernar: en eso consiste precisamente el poder, dicho sea en román paladino. Entre nosotros, clientelismo, partidismo, amiguismo y sectarismo son casi sinónimos. Lo opuesto de buen gobierno: transparencia, independencia institucional (real, no meramente nominal), objetividad y selección de colaboradores mediante el principio de mérito y capacidad, según Ponce (2018).

Vinculado con lo anterior están los supuestos de despilfarro del dinero de los contribuyentes, cuya manifestación más característica son las obras públicas -más o menos innecesarias, más o menos faraónicas- en el pueblo del Ministro que se presenta a candidato, por ejemplo. En la España democrática (y con autonomías regionales y locales de gran alcance en lo competencial y en lo financiero) se trata de un hecho importantísimo y que se encuentra vinculado, vía comisiones en dinero negro de los contratistas, a la financiación de los partidos políticos. ¿A partir de qué punto esas obras públicas (en sí mismas, muy beneficiosas para todos) constituyen por sí, y no sólo por esas comisiones que generan, propiamente corrupción?

Pero ahora no podemos entrar en esos pequeños detalles. 


\section{LOS DATOS}

Preguntarse si en un determinado país (el subrayado es clave) el presidencialismo o el parlamentarismo favorecen la corrupción o por el contrario la perjudican constituye una de esas tesituras en las que los términos del debate no son homogéneos, porque tiene uno que comparar la realidad (lo que existe) con lo que es sólo un escenario contrafactual (el otro) y en el que por tanto todo es cábala.

En cualquier caso, el mero hecho de formularse la cuestión implica una toma de postura en el eterno debate sobre las causas de la corrupción, donde las posiciones son esencialmente tres, aunque con toda suerte de matices o entreveros:

- Causas culturales, para las cuales resulta relevante la famosa teoría del desarrollo moral de Kohlberg, con sus tres niveles: preconvencional, convencional y postconvencional.

- Causas estructurales, que tienen que ver en última instancia con la pobreza y (en menor medida), la desigualdad.

- Causas institucionales, que hoy se entienden las predominantes.

Una vez más, hemos de ir a fuentes internacionales y de estirpe anglosajona (con el sesgo que resulta inevitable), como el Banco Mundial, que entiende que las buenas instituciones son las que cumplen las funciones de promocionar el compromiso, promover la coordinación y generar cooperación, para decirlo con la palabrería de lujo que forma parte de este tipo de discursos. Y sucede que en esos repertorios España y los países de habla hispana no suelen salir bien parados. Por ejemplo, Manuel Villoria Mendieta (2019) ha elaborado la siguiente y nada edificante tabla sobre $\underline{\text { Resultados de la calidad institucional: }}$

\begin{tabular}{|l|c|c|c|c|c|c|c|}
\hline \multicolumn{1}{|c|}{ País } & $\begin{array}{c}\text { Global Com- } \\
\text { petitiveness } \\
\text { report }\end{array}$ & $\begin{array}{c}\text { Easy of } \\
\text { doing } \\
\text { bussiness } \\
\text { Innovation } \\
\text { Index }\end{array}$ & $\begin{array}{c}\text { Indice de } \\
\text { Corrupción } \\
\text { TI (de menor a } \\
\text { mayor corrup- } \\
\text { ción) }\end{array}$ & $\begin{array}{c}\text { Índice de } \\
\text { desarrollo } \\
\text { humano }\end{array}$ & $\begin{array}{c}\text { Rule of Law } \\
\text { Index }\end{array}$ & $\begin{array}{c}\text { UN World } \\
\text { Happiness } \\
\text { report }\end{array}$ \\
\hline 1. Dinamarca & 12 & 3 & 8 & 1 & 4 & 1 & 1 \\
\hline 2. Suecia & 9 & 9 & 2 & 4 & 14 & 4 & 10 \\
\hline 3. Noruega & 11 & 6 & 22 & 6 & 1 & 2 & 4 \\
\hline 4. Suiza & 1 & 31 & 1 & 5 & 3 & & 2 \\
\hline $\begin{array}{l}\text { 5. Nueva } \\
\text { Zelanda }\end{array}$ & 13 & 1 & 17 & 1 & 9 & 8 & 8 \\
\hline 6. Singapur & 2 & 2 & 6 & 7 & 11 & 9 & 22 \\
\hline 7. Finlandia & 10 & 13 & 5 & 3 & 24 & 3 & 5 \\
\hline 8. Holanda & 4 & 28 & 9 & 8 & 5 & 5 & 7 \\
\hline
\end{tabular}




\begin{tabular}{|c|c|c|c|c|c|c|c|}
\hline País & $\begin{array}{c}\text { Global Com- } \\
\text { petitiveness } \\
\text { report }\end{array}$ & $\begin{array}{c}\text { Easy of } \\
\text { doing } \\
\text { bussiness }\end{array}$ & $\begin{array}{c}\text { Global } \\
\text { Innovation } \\
\text { Index }\end{array}$ & $\begin{array}{c}\text { Índice de } \\
\text { Corrupción } \\
\text { TI de menor a } \\
\text { mayor corrup- } \\
\text { ción) }\end{array}$ & $\begin{array}{c}\text { Índice de } \\
\text { desarrollo } \\
\text { humano }\end{array}$ & $\begin{array}{c}\text { Rule of Law } \\
\text { Index }\end{array}$ & $\begin{array}{c}\text { UN World } \\
\text { Happiness } \\
\text { report }\end{array}$ \\
\hline 9. Alemania & 5 & 17 & 10 & 10 & 6 & 6 & 16 \\
\hline España & 32 & 32 & 28 & 41 & 26 & 24 & 37 \\
\hline
\end{tabular}

Ni que decir tiene que el propio autor es el primero en ser consciente de que no estamos ante dogmas de fe: "los países se hallan insertos en inercias históricas muy poderosas", de suerte que no basta con aprobar una norma -la expresión habitual de un propósito modernizador, por así decir- para que la realidad cambie. En última instancia, las causas institucionales no son fácilmente discernibles de las culturales, como señala Villoria Mendieta (2019: 67 a 112).

Lo que hemos llamado buen gobierno, que no tiene una columna propia en ese cuadro, podría entrar en la penúltima ("Rule of law index"), siempre por supuesto que entendamos los parámetros -básicamente, la independencia, empezando por la judicial- en su sentido material y no formal.

Para desarrollar todas esas ideas volvería a hacer falta no ya un Tratado, sino una auténtica Enciclopedia, pero tan noble empeño debe quedar para otra ocasión.

\section{FORMAS DE GOBIERNO}

En suma, asumamos de momento la teoría de que la corrupción tiene causas institucionales (lo sean con carácter de exclusividad o no) y sobre ese fondo proyectemos el dilema presidencialismo/parlamentarismo, en el bien entendido de que en ambos rige la división de poderes, pero, como se ha indicado, en un caso de manera rígida (porque la nación se ve personificada en un individuo, al que ha elegido) y en el otro de forma más flexible, supuesto que primero está el Parlamento, del que el Gobierno surge y ante el que responde, aunque con la contrapartida de poderlo disolver.

$\mathrm{Y}$ no ignorando que ambas formas de gobierno son compatibles con una u otra estructura territorial del Estado.

Sabemos que, al menos desde Aristóteles, el pensamiento humano se suele expresar en términos binarios o de dicotomías (o lo uno o lo otro). Y los ordenadores también están concebidos según esos esquemas binarios. De ello es tributario el par conceptual que ahora nos concierne, del que además cabe decir que, tal y como los manejamos, presidencialismo y parlamentarismo no son sino tipos ideales en el sentido de Max Weber, o sea, ortopedias intelectuales, por así decir: 
"El tipo ideal se logra mediante la acentuación de uno o de varios aspectos y mediante la reunión de un montón de fenómenos individuales existentes que se ajusten a esos aspectos resaltados -de manera difusa o discontinua, aquí más, allá menos, o en algunos sitios nada- en una imagen mental coherente. En la realidad empírica no se puede encontrar esa imagen mental en toda su pureza conceptual: es una utopía, y el trabajo histórico tiene que comprobar en cada caso concreto lo cerca o lo lejos que está la realidad respecto a esa imagen ideal".

Es decir, que:

- Estamos (aun partiendo de la realidad) ante una creación intelectual, una construcción mental pura.

- La selección y realce de algunos aspectos concretos depende del propio investigador, como lo demuestra el propio Weber con los ejemplos de "economía de la ciudad medieval" y de "artesanado".

- Es algo menos simple que la diferencia tradicional entre el género próximo y la diferencia específica. Teniendo cuidado de no querer ir demasiado lejos en lo primero:

“(...) cuanto más amplia sea la validez de un concepto genérico -cuanto mayor sea su extensión-, tanto más nos aleja de la riqueza de la realidad, ya que para que el concepto genérico pueda contener lo que tiene en común el mayor número posible de fenómenos tiene que ser lo más abstracto posible, es decir, tiene que tener un contenido muy reducido".

- Las ciencias culturales sólo pueden trabajar con tipos ideales, por relativo que sea su alcance y sabiendo desde el inicio que la realidad es otra cosa, como manifestó Weber (1904).

Pero también cabe emplear las palabras tipos ideales en otra acepción, más valorativa si se quiere: ideal en el sentido de perfecto -el propio Max Weber hablaba, sí, de la utopía-, al menos a la hora del diseño, aun cuando sabemos que luego en la vida nada se muestra ajeno, ¡ay!, a los agentes de la erosión: el paso del tiempo resulta implacable. De ahí viene precisamente la palabra latina corruptio.

Sobre la denegación de las formas políticas (tres, cada una de ellas con su variante mala) ya disertó nada menos que (otra vez) Aristóteles -democracia/demagogia- y ahora podríamos aplicar ese esquema a las formas de gobierno: el presidencialismo tendría su caricatura en el caudillismo y el parlamentarismo en la partitocracia, por decirlo con dos palabras que todos empleamos a diario con tono de diatriba. 
Pero, aún adoptando sobre presidencialismo y parlamentismo una perspectiva dinámica, al modo de lo que para los alemanes es la Begriffsgeschichte, o sea, la historia de los conceptos, porque sucede en efecto que los conceptos, como las personas y también los lugares, tienen una historia: no siempre han sido como son hoy, supuesto que -es el punto de partida- el óxido hace todo menos descansar, aún así, digo lo cierto es que si no queremos caer en la metafísica resulta procedente razonar sobre la base de referencias concretas. O sea, países con nombre propio, hasta el punto de que, a la vista de las mezclas y las zonas intermedias, quepa plantearse si sustituir el esquema dual (A/B) o por otro meramente gradualista, al modo de lo que hizo Kelsen (1925) a la hora de analizar la centralización y la descentralización: no hay blancos ni negros, sino sólo diversos tonos de grises.

Y así llegamos a la siguiente geografía:

- Presidencialismo: EEUU y por extensión toda América, con particular referencia a México y los Estados del centro y del sur. La propia Argentina, sin duda, entre ellos.

En el bien entendido de que, como se ha acreditado recientemente, en los países de Iberoamérica, teóricamente presidencialistas, los reglamentos de las Cámaras están arbitrando unas técnicas de control del poder ejecutivo que en poco se distinguen de las del modelo parlamentario, como afirma García Roca (2016) y, previamente, Ackerman (2007).

- Parlamentarismo: El paradigma sigue estando en UK, donde resulta indisociable de la monarquía en la Jefatura del Estado y su evolución a lo largo de los siglos sin perjuicio de su desnaturalización en los últimos años (sin que exista texto constitucional que le pueda servir de barrera), como acredita el hecho de que desde 2011 el Premier ha perdido la prerrogativa de disolver la Cámara de los Comunes y convocar elecciones ${ }^{2}$ o, más aún, la circunstancia, verdaderamente sísmica, de la introducción de mecanismos de democracia directa o referéndum, como ha sucedido en relación con la permanencia de Escocia en el Reino Unido o con su condición de partícipe en la integración europea ${ }^{3}$. Un esquema similar es el que existe en las otras monarquías (Benelux, País Escandinavo y desde 1978 España). Pero también hay parlamentarismo con República, como Italia a partir de 1947 -aunque con 1992, con

2 Es la llamada Fixed-Term-Parliaments Sct, aprobada en 2011, y que establece elecciones cada cinco años (a contar desde el primer martes de mayo) y que reduce los supuestos de comicios anticipados a una moción de censura o el voto de dos tercios de la Cámara de los Comunes.

3 Y ello sin perjuicio de la Sentencia del High Court of Justice de 3 de noviembre de 2016, que, a instancias de una persona particular, Gina Miller, declaró que el Parlamento tenía que dar su OK antes de que el Gobierno, conforme al Art. 50 del Tratado de la Unión Europea, pudiera hacer uso de su facultad de irse de la Unión. Toda una reparlamentarización, si se permite tan horrible palabra. 
el estallido en mil pedazos del sistema de partidos, como tournant- y Alemania desde el venturoso 1949 .

En suma, Europa, cierto que los matices de Francia (1958) y Portugal. Sobre todo, el primero de ellos, con una teoría de las fuentes del derecho muy curiosa y en la que coexisten, de manera esquizofrénica, la reserva material de ley y el carácter limitado (a esos campos) de los contenidos posibles de las mismas.

Si nos expresamos en términos geográficos más que conceptuales, diríamos que el presidencialismo es genuinamente americano (como el jinete del caballo de Marlboro, para entendernos) y el parlamentarismo europeo (como los bistrots de París o los cafés de Viena). Pero con muchos matices dentro de cada uno de los dos continentes.

\section{NOTAS SOBRE LA REALIDAD ACTUAL}

Y además sabiendo que en los últimos tiempos los componentes personalistas de los liderazgos (todos, así sea una u otra la forma de gobierno) se han acentuado. Ejemplos:

Trump en EEUU.

López Obrador en México.

Macron en Francia.

En España, los dos partidos surgidos en los últimos años como reacción frente a lo que se indicó más arriba, o sea, a la crisis iniciada en 2007/2008 y el descubrimiento, debido sobre todo a causas tecnológicas, de la corrupción institucional de alcance sistemático en la que estábamos instalados ("no nos representan"), Podemos y Ciudadanos, son no sólo tan personalistas como los antiguos -PSOE y PP- sino mucho más, si cabe, como señala Caño (2019).

\section{CONCLUSIÓN}

Mi tesis, pensada sobre todo en España y asumiendo al menos en parte la teoría de la casualidad institucional, consiste en señalar que la percepción de que en los parlamentarismos hay menos corrupción que en los presidencialismos no se ve confirmada por la realidad. Dicho de otra manera: no creo que si hubiésemos tenido una forma de gobierno presidencialista las cosas hubiesen sido mejores o menos malas. Lo único que sucede es que (sobre todo, en un régimen de autonomías territoriales, es decir, de pluralismo por así decir vertical, y con unas estructuras partidarias carísimas de mantener, pese a la rebaja de precios de las campañas electorales que suponen 
las nuevas tecnologías al ser gratis la comunicación) parece estar más dispersa o por así decir repartida: es, como se dice en España, transversal, al ir por lotes o cuotas según la proporción de votos y escaños de cada partido. Lo que no le quita un ápice de gravedad.

Hay que poner datos, por supuesto, y ahora sí acreditados. Me fijo en los del despilfarro de infraestructuras en España, según un Informe de la Universidad de Valencia de 2018: "en el período 1985-1995, de 15.217 millones de euros o cerca de un 5\% del PIB del año 1995; pero en el período del llamado boom económico o la década dorada (1996-2007), la magnitud del despilfarro alcanzó ya un 20\% del PIB de 2007 con 14.732 millones de euros despilfarrados, aunque sea imposible determinar con exactitud el monto preciso de esa cantidad que es atribuible directamente a la corrupción", como señala Romero y otros (2018). Resulta evidente que nuestra forma de gobierno parlamentaria, o sea, partitocrática (y, además, se insiste, de pluralismo territorial) esté en la raíz de ello. De lo que habría sucedido -caeteris paribus en lo que hace a los demás factores- con un sistema presidencialista sólo podemos fabular. Pero con toda probabilidad los números habrían sido menos y desde luego no superiores.

Dicho de otra manera y como conclusión: el grado de corrupción, que es muy variable, depende de hechos ajenos a la forma de gobierno presidencialista o parlamentaria. Probablemente, los factores institucionales no son los más importantes, porque, aunque con apariencias idénticas, las culturas políticas (o las culturas sin más) hacen que las cosas sean muy diferentes.

En suma, se podrá discutir si los instrumentos de medida de calidad institucional que se manejan, y que ya hemos expuesto, son completos o incompletos. Pero lo cierto es que no existe ningún motivo para pensar que hubiera que añadir una variable sobre la forma de gobierno.

La mayor información (el rasgo distintivo de nuestro tiempo, a diferencia de lo que sucedía en la Argentina de Perón y la Italia de Berlusconi) sí puede resultar determinante, pero tampoco es un dato definitivo. Hay pueblos que saben cómo son sus gobernantes (la Cataluña de Jordi Pujol) y siguen votando a esa misma persona o a sus herederos. Incluso con entusiasmo renovado.

Al final, volvemos a lo de siempre, las causas culturales, es decir, la conciencia social. O sea, la educación. La de las escuelas y la de la familia. Lo que los franceses llaman "les mentalités".

Madrid, 11 de noviembre de 2019. 


\section{BIBLIOGRAFÍA:}

- ABC (2018), "La corrupción en España cuesta 90.000 millones de euros anuales, según un estudio", noticia aparecida en el Periódico de 8 de diciembre de 2018, 08-12-2018.

- Ackermann, Bruce (2007), La nueva división de poderes, México, Fondo de Cultura Económica.

- Betancor, Andrés (2017), “Corrupción: conceptos, tipos, perjuicios, causas, consecuencias", en Corrupción, corrosión del Estado de Derecho, Andrés Betancor (Dir.), Cizur Menor, Aranzadi.

- Caño, Antonio (2019), "Democracias narcisistas", noticia aparecida en el $\mathrm{Pe}^{-}$ riódico El País, de 18 de mayo de 2019, 18-05-2019.

- García Roca, Javier (2016), "Control parlamentario y convergencia entre presidencialismo y parlamentarismo", en Revista UNED Teoría y realidad constitucional, núm. 38, pp. 61-99.

- Kelsen, Hans (2015), Allgeweine Staatslehre, con traducción al español, Teoría general del Estado, $5^{\text {a }}$ edición, México, Coyoacán.

- Ponce Solé, Juli (2018), "La lucha por el buen gobierno y el derecho a una buena administración mediante el estándar jurídico de la diligencia debida”, Alcalá de Henares, Universidad de Alcalá de Henares.

- Romero, Juan y otros (2018), "Aproximación a la geografía del despilfarro en España: balance de las últimas dos décadas", en Boletín de la Asociación de Geógrafos Españoles, núm. 77, pp. 1-51.

- Transparencia Internacional (2018), "Índice de Percepción de la Corrupción de 2017” (2018), en Página Web de Transparencia Internacional, febrero, https:// www.transparency.org/news/feature/corruption perceptions index 2017, 10-062019 .

- Villoria Mendieta, Manuel (2019), “Combatir la corrupción”, en Serie Más Democracia, Barcelona, Gedisa.

- Weber, Max (2009), "La objetividad del conocimiento en la ciencia social y en el conocimiento de la política social", en Archiv für Sozialwissenschalf und Sozial Politik, Joaquín Abellán (edi. y Estudio Preliminar) Madrid, Alianza.

\section{RESEÑA BIOGRÁFICA:}

Antonio Jiménez-Blanco (Granada, 1957), de nacionalidad española, es Letrado de las Cortes Generales en situación de excedencia, Catedrático de Derecho 
Administrativo (Universidad Politécnica de Madrid) y Abogado. Especialista en regulación económica e integración europea. Sus últimos trabajos han sido recogidos en el libro "España, Europa, Globalización: la modernización del Derecho", Global Law Press, 2019.

\section{GUADROS, TABLAS Y GRÁFICAS:}

Las dos incluidas en el texto, o sea:

Índice de percepción de corrupción según Transparencia Internacional

\begin{tabular}{|c|c|c|c|c|}
\hline $\begin{array}{c}\text { Ranking de países } \\
2016 \text { (sobre } 176 \\
\text { países) }\end{array}$ & Países iberoamericanos & 2016 Puntos & 2014 Puntos & 2012 Puntos \\
\hline 21 & Uruguay & 71 & 73 & 72 \\
\hline 24 & Chile & 66 & 73 & 72 \\
\hline 29 & Portugal & 62 & 63 & 63 \\
\hline 41 & España & 58 & 60 & 65 \\
\hline 41 & Costa Rica & 58 & 54 & 54 \\
\hline 60 & Cuba & 47 & 46 & 48 \\
\hline 79 & Brasil & 40 & 43 & 43 \\
\hline 87 & Panamá & 38 & 37 & 38 \\
\hline 90 & Colombia & 37 & 37 & 36 \\
\hline 95 & Argentina & 36 & 34 & 35 \\
\hline 95 & El Salvador & 36 & 39 & 38 \\
\hline 101 & Perú & 35 & 38 & 38 \\
\hline 113 & Bolivia & 33 & 35 & 34 \\
\hline 120 & Re. Dominicana & 31 & 32 & 32 \\
\hline 120 & Ecuador & 31 & 33 & 32 \\
\hline 123 & Honduras & 30 & 29 & 28 \\
\hline 123 & México & 30 & 35 & 34 \\
\hline 123 & Paraguay & 30 & 24 & 25 \\
\hline 136 & Guatemala & 28 & 32 & 33 \\
\hline 145 & Nicaragua & 26 & 28 & 29 \\
\hline 166 & Venezuela & 17 & 19 & 19 \\
\hline
\end{tabular}


$\underline{\text { Resultados de la calidad institucional }}$

\begin{tabular}{|l|c|c|c|c|c|c|c|}
\hline \multicolumn{1}{|c|}{ País } & $\begin{array}{c}\text { Global } \\
\text { Competi- } \\
\text { tiveness } \\
\text { report }\end{array}$ & $\begin{array}{c}\text { Easy of } \\
\text { doing } \\
\text { bussiness }\end{array}$ & $\begin{array}{c}\text { Global } \\
\text { Innovation } \\
\text { Index } \\
\text { Corrupción TI } \\
\text { (de menor a } \\
\text { mayor corrup- } \\
\text { ción) }\end{array}$ & $\begin{array}{c}\text { Índice de de } \\
\text { Indesarrollo } \\
\text { humano } \\
\text { of Law } \\
\text { Index }\end{array}$ & $\begin{array}{c}\text { Happiness } \\
\text { report }\end{array}$ \\
\hline 1. Dinamarca & 12 & 3 & 8 & 1 & 4 & 1 & 1 \\
\hline 2. Suecia & 9 & 9 & 2 & 4 & 14 & 4 & 10 \\
\hline 3. Noruega & 11 & 6 & 22 & 6 & 1 & 2 & 4 \\
\hline 4. Suiza & 1 & 31 & 1 & 5 & 3 & & 2 \\
\hline $\begin{array}{l}\text { 5. Nueva } \\
\text { Zelanda }\end{array}$ & 13 & 1 & 17 & 1 & 9 & 8 & 8 \\
\hline 6. Singapur & 2 & 2 & 6 & 7 & 11 & 9 & 22 \\
\hline 7. Finlandia & 10 & 13 & 5 & 3 & 24 & 3 & 5 \\
\hline 8. Holanda & 4 & 28 & 9 & 8 & 5 & 5 & 7 \\
\hline 9. Alemania & 5 & 17 & 10 & 10 & 6 & 6 & 16 \\
\hline España & 32 & 32 & 28 & 41 & 26 & 24 & 37 \\
\hline
\end{tabular}

